\title{
Uma Visão Processual dos Direitos Fundamentais
}

\section{Tiago Astor Rocha Lima}

Mestrando em Direito pela Universidade Federal do Ceará (UFC), Advogado do Escritório Rocha, Marinho e Sales Advogados S/S, Professor de Direito Civil IV (Família) da Faculdade 7 de Setembro (FA7). 



\section{Uma Visão Processual dos Direitos Fundamentais}

\section{IDA JuRisdição Constitucional}

A temática que se objeta tratar envolve por natureza a análise do conceito de jurisdição constitucional, especialmente tendo em vista a perspectiva dos direitos fundamentais como aqueles direitos protegidos processualmente e dotados de um status especial por cada Constituição, características estas que os distinguem dos demais direitos positivados no restante do ordenamento jurídico ${ }^{1}$.

Noutras palavras, se se concebem os direitos fundamentais como aqueles direitos encartados na Lei Suprema de uma nação, faz-se imperioso o asseguramento tanto das normas materiais como processuais nela previstas, conferindo-lhes assim a máxima eficácia. Resta assim indissociável o conhecimento da jurisdição constitucional.

Gérson Marques ${ }^{2}$, com singularidade, pontua acerca da existência do sentido formal e do sentido material da jurisdição constitucional, sendo o primeiro, já insuficiente, baseado no órgão que a exerce, enquanto que o segundo seria compreendido através de um procedimento adequado à garantia da aplicabilidade da Constituição. Deveras, hodiernamente já se superou a ótica da jurisdição constitucional tendo em conta o órgão competente, mesmo porque na maioria dos ordenamentos a aplicação dos mandamentos constitucionais, entre eles as normas de direitos fundamentais, não se dá em apenas um órgão jurisdicional, mas em vários, em face da possibilidade do controle difuso de constitucionalidade.

${ }^{1}$ ROBLES, Gregorio. Los derechos fundamentales e la ética em sociedad actual. Madrid: Civitas, 1995, p. 20.

${ }^{2}$ LIMA, Francisco Gérson Marques de. Fundamentos constitucionais do processo (sob a perspectiva de eficácia dos direitos e garantias fundamentais). São Paulo: Malheiros, 2002, pp. 16/17. 
Nesse contexto e especialmente no caso brasileiro é que se revela a importância da jurisdição constitucional, pois independentemente da instância (justiça ordinária ou justiça constitucional - Supremo Tribunal Federal) será possível garantir a supremacia dos princípios e regras constitucionais, buscando por conseguinte a máxima eficácia aos direitos fundamentais.

Com efeito, não se deve olvidar que o fato dos direitos fundamentais possuírem resguardo nas Constituições torna não só a justiça ordinária, mas principalmente a justiça constitucional (STF), instituições essenciais para a tutela dos direitos fundamentais ${ }^{3}$.

\section{A Importância de uma Corte Constitucional}

As Cortes Constitucionais nos moldes existentes atualmente em diversos países da Europa, como Alemanha, França, Espanha, Portugal e Itália, derivam notadamente das idéias propostas por Hans Kelsen e que serviram de fundamento para a criação dos primeiros tribunais constitucionais, a saber, da antiga Tchecoslováquia e da Áustria em meados de $1920^{4}$.

Esses Tribunais ou Cortes Constitucionais têm por objetivo precípuo atuar como órgão intérprete e aplicador das Leis Supremas, servindo como uma justiça propriamente constitucional, porquanto limitada a sua competência de atuação, abrangendo tão somente questões referentes ao controle de constitucionalidade das leis, a análise de recursos envolvendo matéria eminentemente constitucional (e.g. afronta a direitos fundamentais) e outras causas de relevante interesse, excluindo-se a atividade revisora, que atualmente descaracteriza a feição constitucional do Supremo Tribunal Federal e que juntamente com o processo de escolha de seus membros é motivo de severas críticas por alguns renomados doutrinadores ${ }^{5}$.

No entanto, o tema em alusão ainda suscita inúmeras controvérsias na própria literatura jurídica especializada no que concerne à natureza e legitimidade das

\footnotetext{
${ }^{3}$ ROLLA, Giacarlo. Derechos fundamentales, Estado democrático y justicia constitucional. México: UNAM, 2002, p. 133-180, apud FIX-ZAMUDIO, Héctor. Breves reflexiones sobre la naturaleza, estructura y funciones de los organismos jurisdiccionales especializados en la resolución de procesos constitucionales. Revista latino-americana de estudos constitucionais, n.I - jan/jun, Belo Horizonte: Del Rey, 2003, p. 102.

${ }^{4}$ FIX-ZAMUDIO, Héctor. Ob. cit., p. 79.

${ }^{5}$ GUERRA FILHO, Willis Santiago. Processo constitucional e direitos fundamentais. $3^{\mathrm{a}}$. ed. São Paulo: Celso Bastos Editor: Instituto Brasileiro de Direito Constitucional, 2003,p. 17.
} 
decisões das Cortes Constitucionais. Quanto à natureza dos Tribunais Constitucionais, tem-se debatido, como bem informa Héctor Fix-Zamudio ${ }^{6}$, que esses órgãos responsáveis pela materialização dos valores constitucionais poderiam atuar como um legislador negativo ou ainda como um novo poder diverso dos três tradicionalmente existentes, sem questionar-se o seu caráter político, jurídico ou misto.

Em verdade, caracterizar as Cortes Constitucionais como um órgão político ou jurídico, ou ainda como um legislador negativo ou um órgão constitucional autônomo do Poder Judiciário é questão de bem menor relevância do que se saber o seu real e capital escopo.

Funcionar como instância fundamental e definitiva na concretização dos valores constitucionais, os quais são os próprios alicerces dos princípios e regras, servindo ademais como orientação aos juízes ordinários quando do exercício do controle concentrado de constitucionalidade, este é o verdadeiro objeto de uma Corte Constitucional.

Registre-se, ainda, que a (in)observância pelas instâncias ordinárias das decisões emanadas destes órgãos encarregados de dar a última palavra em matéria constitucional dependerá não do caráter político, jurídico, de legislador negativo ou de poder autônomo desses órgãos, mas sim da autoridade material de suas decisões, que advém através de uma bem elaborada exegese dos preceitos constitucionais. Não basta, portanto, haver hierarquia simplesmente formal, faz-se inarredável um mínimo de legitimidade de suas decisões.

Todavia, não é tão simples alcançar esse mínimo de legitimidade dos pronunciamentos emanados das Cortes Constitucionais, pois leva ao ingresso no estudo da própria legitimidade da escolha dos membros destes órgãos jurisdicionais. No exemplo brasileiro, muito se questiona a legitimidade dos Ministros do STF, pois são nomeados pelo Presidente da República, dentre cidadãos de ilibada reputação e notável saber jurídico com idade entre trinta e cinco e sessenta e cinco anos.

A dúvida sobre a legitimidade dos integrantes destas Supremas Cortes de Justiça está na possibilidade de pessoas nomeadas pelo Chefe do Executivo atuarem como legislador negativo ou positivo em situações envolvendo, verbi gratia, o julgamento de Ações Diretas de Inconstitucionalidade (ADIn) e

${ }^{6}$ FIX-ZAMUDIO, Héctor. Ob. cit., p. 85. 
Ações Declaratória de Constitucionalidade (ADC), uma vez que nesses casos a decisão do órgão jurisdicional poderá ser de expurgar do ordenamento jurídico uma norma aprovada pelo Congresso Nacional, onde se encontram os representantes do povo brasileiro, eleitos mediante o voto direto e secreto.

Oportuno observar que não se busca através do presente estudo traçar regras fixas e objetivas de escolha dos membros das mais altas Cortes de Justiça, mesmo porque não se chegaria a uma unanimidade. Entrementes, nesse ensejo interessa destacar proposta de Héctor Fix-Zamudio acerca de uma maneira de se alcançar legitimidade dos órgãos constitucionais e conseqüentemente de suas decisões:

la legitimidad de origen de los organismos jurisdiccionales especializados en la resolución de los conflictos constitucionales se apoya en los cuidadosos sistemas de preparación, selección y nombramiento, generalmente por los otros órganos políticos del Estado, y su legitimidad de ejercicio se apoya en la prudencia y sensibilidad tanto jurídica como política, para realizar una interpretación constitucional que permita la más adecuada protección de las normas y de los derechos fundamentales. ${ }^{7}$

Destarte, clarividente que a forma de nomeação dos integrantes dos Tribunais Constitucionais podem, ou devem, influir na legitimidade de suas decisões, mas estas não dependem única e exclusivamente do modo de escolha de seus membros, pelo contrário, essa questão é até de menor importância, tomando por consideração o elevado grau de influência do conhecimento jurídico, político, social e econômico do magistrado constitucional para que se alcance uma decisão lastreada nos valores escolhidos pela sociedade e positivados em sua Carta Maior.

Antenado nesta alta relevância das Cortes Constitucionais é que se tem admitido que estes órgãos supremos exerçam papel essencial do próprio Estado Democrático de Direito ${ }^{8}$. E não se poderia imaginar doutra forma, visto que é na justiça propriamente constitucional, como dantes explanado,

\footnotetext{
${ }^{7}$ Idem, p. 94.

${ }^{8}$ GUERRA FILHO, Willis Santiago. Ob. cit., p. 18.
} 
que se concretizam e se tornam eficazes os valores consagrados constitucionalmente, dentre os quais os direitos e garantias fundamentais.

\section{i) Processo Constitucional e o} Estado Democrático de Direito

Não bastam aos jurisdicionados a existência de direitos e garantias fundamentais e de uma jurisdição propriamente constitucional para que os efetive e materialize, faz-se também tão imprescindível a presença de instrumentos processuais a servirem de tutela a estes direitos e garantias. Ou melhor, é exigência do Estado Democrático de Direito que os direitos fundamentais possam ser objeto de defesa pelos seus titulares, extraindose de efeito a sua íntima relação com o processo constitucional.

Calha trazer a lume a seguinte observação de Jorge Miranda:

A primeira forma de defesa dos direitos é a que consiste no seu conhecimento. Só quem tem consciência dos seus direitos consegue usufruir os bens a que eles correspondem e sabe avaliar as desvantagens e os prejuízos que sofre quando não os pode exercer ou efectivar ou quando eles são violados ou restringidos. ${ }^{9}$

Logo, o conhecimento de um direito consiste no primeiro mecanismo de defesa posto ao cidadão. De nada vale um instrumento processual a uma pessoa que sequer sabe da existência de um direito passível de por ela ser invocado. O inverso, ou seja, a existência de direitos sem a devida tutela jurisdicional, também acaba por tornar inútil o próprio direito material, em vista da possibilidade de ser desrespeitado sem que subsista ao cidadão um meio de defesa.

Com efeito, faz-se mister que o ordenamento jurídico acolha mecanismos processuais de defesa dos direitos e garantias fundamentais por ser decorrência do próprio Estado Democrático de Direito. Nas palavras de José Alfredo de Oliveira Baracho:

\footnotetext{
${ }^{9}$ MIRANDA, Jorge. A tutela jurisdicional dos direitos fundamentais em Portugal. Direito constitucional: estudos em homenagem a Paulo Bonavides. São Paulo: Malheiros, 2003, p.284.
} 
Torna-se cada vez mais importante o aperfeiçoamento dos instrumentos processuais que completem o papel do processo constitucional na efetivação da cidadania plena. Como titulares de direito, os cidadãos, no exercício da cidadania plena, não podem ser impedidos do gozo de seus múltiplos direitos, reconhecidos e elencados na Constituição e na legislação infraconstitucional, mesmo daqueles cujas leis não foram promulgadas ou que se tornem menos efetivos e eficazes na ausência destas. ${ }^{10}$

As ações constitucionais, aquelas destinadas à proteção dos direitos e garantias fundamentais, constituem meios de participação política e de exercício da cidadania, mostrando-se como remédios processuais adequados a fazer valer os direitos violados ou ameaçados de lesão.

Insta averbar, ainda, que o conceito de cidadania atualmente vigente já não mais se resume à simples possibilidade de votar, tendo sido escorreitamente elastecido para englobar todas as formas do cidadão participar das decisões estatais, cobrando e exigindo posturas e atitudes do Estado para a satisfação das necessidades do povo ${ }^{11}$.

Ainda com relação às ações constitucionais, cumpre destacar que o Estado brasileiro, longe de qualquer dúvida ou entredúvida, concentra em seu ordenamento jurídico um dos mais avançados programas de ações constitucionais, muito embora ainda não suficiente para tornar plenamente eficazes os direitos fundamentais previstos na Constituição Federal de 1988. Dentre os remédios constitucionais pátrios, pode-se citar os mais clássicos, como o Mandado de Segurança e o Habeas Corpus, e outros como a Ação Direta de Inconstitucionalidade, a Ação Declaratória de Constitucionalidade, a Ação Popular, a Ação Civil Pública, a Ação de Descumprimento de Preceito Fundamental, o Habeas Data e ainda o Mandado de Injunção, este de origem brasileira.

Esta amplitude de ações que têm por objeto a defesa dos valores constitucionais talvez decorra do ainda período de exceção que o Estado brasileiro atravessou durante as décadas de 60,70 e 80 do século passado.

${ }^{10}$ BARACHO, José Alfredo de Oliveira. Teoria geral da cidadania: a plenitude da cidadania e as garantias constitucionais e processuais. São Paulo: Saraiva, 1995, p. 55.

${ }^{11}$ LIMA, Francisco Gérson Marques de. Ob. cit., p. 99/100. 
Nada obstante a diversidade de instrumentos processuais de proteção e resguardo dos direitos e garantias fundamentais, Gérson Marques observa que os instrumentos e garantias processuais, por se inspirarem no status negativus, ainda são defícientes principalmente no que tange aos direitos que exigem prestações do Estado ${ }^{12}$. Partindo-se desta premissa inteiramente válida e acertada, colhe-se que o grau de eficácia dos direitos fundamentais é inversamente proporcional ao avanço de suas dimensões ou gerações, carecendo ao cidadão, exempli gratia, meios processuais eficazes de discussão dos atos governamentais.

Sem embargo da carência de ações próprias à defesa principalmente dos direitos de terceira e quarta geração, cumpre aduzir que as decisões proferidas nas ações constitucionais possuem natureza essencialmente mandamental, porquanto tem por fito a proteção dos valores fundamentais de um país, não podendo estar à mercê de um novo processo destinado a garantir a sua execução.

Desta feita, sobressai-se absolutamente incompatível com a própria natureza dos direitos fundamentais que as decisões envolvendo esta matéria necessitassem de uma outra ação. Por conseguinte, tem se revelado que as decisões que envolvam direitos fundamentais necessitam de auto-executabilidade.

Ademais, na tutela dos direitos fundamentais verifica-se, de forma até permanente, o periculum in mora, ou melhor, a possibilidade de ineficácia da prestação jurisdicional acaso se aguarde o final julgamento da ação, de sorte que não faria o menor sentido ter que se aguardar também por uma ação executiva. Baseado nesta natureza dos direitos fundamentais, Konrad Hesse $^{13}$ elucida que o Tribunal Constitucional Federal da Alemanha admite que esses direitos detêm garantia à proteção jurídica efetiva, pois uma tardia decisão judicial pode prejudicar a validez efetiva dos direitos fundamentais. As idéias traçadas acima se sobressaem como fundamentais para o entendimento do plexo existente entre o processo constitucional e o Estado Democrático de Direito, visto que os direitos fundamentais carecem de plena eficácia, fato este que só se mostra possível diante da existência de mecanismos de tutela próprios, por se tratarem de direitos consagrados constitucionalmente.

${ }^{12}$ Idem, p. 37/38.

${ }^{13}$ HESSE, Konrad. Elementos de direito constitucional da República Federal da Alemanha. Tradução (da 20a . edição alemã) de Luís Afonso Heck. Porto Alegre: Sergio Antonio Fabris Editor, 1998, p. 270. 


\section{Direitos Fundamentais Processuais}

A possibilidade de o particular invocar uma tutela judicial em defesa de um interesse individual ou coletivo decorre do direito de ação, ao qual inúmeras nomenclaturas podem ser dadas e dentre as quais se pode destacar o de direito à inafastabilidade do controle jurisdicional, de direito ao acesso à justiça, de garantia da via judicial (Alemanha) ${ }^{14}$, garantia de acesso aos tribunais

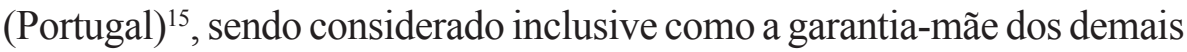
direitos $^{16}$.

Sobre o acesso à justiça, Mauro Cappelletti em singular definição pontua:

O acesso à justiça pode, portanto, ser encarado como o requisito fundamental - o mais básico dos direitos humanos - de um sistema jurídico moderno e igualitário que pretenda garantir, e não apenas proclamar os direitos de todos. ${ }^{17}$

O direito de ação deve realmente ser visualizado como uma das mais importantes garantias do Estado Democrático de Direito, levando-se em consideração que não se cumpriria a finalidade de um direito material sem o adequado direito processual, assim como não se atinge o objetivo do direito processual se há restrições ao acesso à justiça, pois numa sociedade civilizada não mais se admite, em termos gerais, fazer justiça com as próprias mãos.

Desta maneira, resta facilitado o entendimento de que não se pode admitir a imposição de obstáculos desproporcionais ao acesso à justiça, sob pena de se estar a restringir a própria eficácia de direitos fundamentais, que em muitas situações dependem da atuação do Poder Judiciário para que sejam realizados.

Em verdade, empecilhos não faltam ao efetivo exercício do direito de ação, intimidando a parte de recorrer ao Estado para impedir lesão ou ameaça a direito, podendo-se citar as custas judiciais (despesas processuais e honorários advocatícios), a falta de possibilidade das partes para arcar com um processo, a demora na prestação jurisdicional etc ${ }^{18}$.

\footnotetext{
${ }^{14}$ Idem, p. 269.

${ }^{15}$ CANOTILHO, J.J. Gomes. Direito constitucional. Coimbra: Livraria Almedina, 1991, pp. 665/666.

${ }^{16}$ LIMA, Francisco Gérson Marques de. Ob. cit., p. 51.

${ }^{17}$ CAPPELLETTI, Mauro e GARTH, Bryant (colab). Acesso à justiça, trad. Ellen Gracie Northfleet. Porto Alegre: Sergio Antonio Fabris Editor, 2002, p. 12.

${ }^{18}$ Idem, p. 15/29.
} 
Demais disso, não é à toa que se concebe o direito de ação como algo inerente ao Estado Democrático de Direito, pois outros direitos fundamentais processuais somente serão passíveis de se perfectibilizar diante de sua plena realização.

Assim ocorre com o devido processo legal, o qual também é base elementar e originária de outros direitos processuais. $\mathrm{O}$ due process of law, na expressão originária, engloba questões de alta relevância para a concretização eficaz dos direitos fundamentais, não se limitando unicamente ao direito das partes ao processo justo e equânime nos termos legais, mesmo porque a expressão por si só cuida de dar-lhe um significado à sua altura.

Um processo para que seja devido e de acordo com os ditames legais deve promover às partes igualdade de armas nas situações que se desenrolarem durante todo o procedimento. Nesta esteira, o processo somente estará cumprindo a sua função legal caso suas decisões possuam algum resultado considerado útil, pois se assim não fosse a parte autora não necessitaria ter ingressado judicialmente em busca da proteção de seu direito. Logo, deve ser inerente ao processo que as decisões possuam executoriedade, fato este que muitas vezes depende inclusive de que sejam proferidas em prazo razoável.

O direito ao contraditório e à ampla defesa, conquanto em muitos ordenamentos estejam positivados isoladamente do devido processo legal, expressam uma de suas ramificações, sendo responsáveis por garantir às partes a apresentação de defesas proporcionais à consagração do direito em debate. É corolário dos direitos acima comentados o direito à independência judicial e ao juiz natural, em função de sua essencialidade à promoção da justiça. José Alfredo de Oliveira Baracho alerta sobre a importância de tais direitos:

A função jurisdicional coloca os juízes submetidos unicamente à lei. A independência judicial, em qualquer de seus aspectos, tem como destinatário o juiz, como administrador da justiça, que, exercendo o poder jurisdicional ou a função jurisdicional, aplica a norma ao caso concreto, condição básica da imparcialidade judicial, que vai orientar a objetividade da sentença, constituindo uma 
garantia essencial para os jurisdicionados. Para atingir essa independência propugna-se liberar o juiz de influências externas, gerando o autogoverno. ${ }^{19}$

Calha ainda mencionar que os cidadãos para que tenham seus direitos efetivados necessitam que exista uma estruturada organização não só do Poder Judiciário, mas também dos demais órgãos estatais. No âmbito do Judiciário, pode-se citar a exigência do Ministério Público, da Ordem dos Advogados, da Defensoria Pública, da Magistratura, dos servidores da justiça, dentre outros, que através de recíproca colaboração garantem o direito de obter justiça.

Os direitos fundamentais processuais dantes observados foram apenas exemplos de como as legislações dispõem de meios inerentes à processualística e que devem ser objeto de ampla observação pelo Estado, ou melhor, pelos que exercem as suas funções, de modo que se deixou de mencionar outros direitos e garantias pelo propósito deste resumido estudo.

\section{i) O Direito Processual Constitucional}

Ao cabo destas idéias, faz-se oportuno reconhecer que, em passos desproporcionais à sua importância, tem tomado corpo o ramo do direito processual constitucional, dissociando-se da teoria geral do processo, com objeto nitidamente próprio e destinado ao estudo dos institutos processuais com resguardo na Constituição ${ }^{20}$, em busca de realizar a vontade constitucional $^{21}$, levando ao máximo de eficácia possível as normas reguladoras do processo.

Deveras, objeto de estudo é o que não falta ao direito processual constitucional, cabendo-lhe a pesquisa não só dos direitos e garantias do processo com repouso constitucional, pois o campo de sua abrangência conduz também à investigação das ações constitucionais, que não são poucas, além dos procedimentos específicos próprios da jurisdição constitucional.

O crescente advento deste ramo do direito processual insere-se ainda com maior amplitude em um momento de grande e criticável instabilidade

\footnotetext{
${ }^{19}$ BARACHO, José Alfredo de Oliveira. Ob. cit., p. 13.

${ }^{20}$ LIMA, Francisco Gérson Marques de. Ob. cit., p. 123/130.

${ }^{21}$ HESSE, Konrad. A força normativa da constituição. Tradução Gilmar Ferreira Mendes. Porto Alegre: Sergio Antonio Fabris Editor, 1991, passim.
} 
constitucional, elevando ainda mais sua importância, pois pode se mostrar a seara competente e responsável para a solução de impasses até então insolúveis pelos demais ramos jurídicos.

\section{[i] Conclusões}

Daquilo que se delineou ao longo do tema, podem ser extraídas algumas inevitáveis conclusões:

Tem se mostrado essencial para a tutela dos direitos e garantias fundamentais a jurisdição constitucional, porquanto o seu campo de atuação envolve exatamente a aplicação e interpretação das normas constitucionais;

A existência de uma Corte Constitucional, atuando como instância fundamental e definitiva na concretização dos valores constitucionais, inserese como instituição essencial do próprio Estado Democrático de Direito;

O processo constitucional, através de uma vasta gama de instrumentos processuais, destina-se a garantir a máxima efetividade dos direitos e garantias fundamentais presente num Estado Democrático de Direito, muito embora as ações constitucionais ainda não tenham evoluído ao mesmo passo que as diversas gerações de direitos fundamentais;

Alguns direitos fundamentais processuais, como o direito de ação, ao devido processo legal, ao contraditório e à ampla defesa, à organização estrutural dos órgãos estatais, à independência judicial e ao juiz natural, devem ser observados pelos exercentes das funções estatais em prol do direito à justiça;

O ramo do direito processual constitucional tem exsurgido como próprio ao estudo dos institutos processuais com resguardo na Constituição, buscando o máximo de eficácia às normas reguladoras do processo e a solução de impasses até então insolúveis pelos demais ramos do Direito. 


\section{Bibliografia}

BARACHO, JoséAlfredo de Oliveira. Teoria geral da cidadania: a plenitude da cidadania e as garantias constitucionais e processuais. São Paulo: Saraiva, 1995.

BONAVIDES, Paulo (coord.). Revista latino-americana de estudos constitucionais, n.I-jan/jun, Belo Horizonte: Del Rey, 2003.

CANOTILHO, J.J. Gomes. Direito constitucional. Coimbra: Livraria Almedina, 1991.

CAPPELLETTI, Mauro e GARTH, Bryant (colab). Acesso à justiça. Original: Access to justice: the worldwide movement to make rights effective. A general report. Tradução Ellen Gracie Northfleet. Porto Alegre: Sergio Antonio Fabris Editor, 2002.

GRAU, Eros Roberto e GUERRA FILHO, Willis Santiago. Direito Constitucional: estudos em homenagem a Paulo Bonavides. São Paulo: Malheiros, 2003.

GUERRA FILHO, Willis Santiago. Processo constitucional e direitos fundamentais. $3^{\text {a }}$. ed. São Paulo: Celso Bastos Editor: Instituto Brasileiro de Direito Constitucional, 2003.

HESSE, Konrad. A força normativa da constituição. Original: Die normative kraft der verfassung. Tradução Gilmar Ferreira Mendes. Porto Alegre: Sergio Antonio Fabris Editor, 1991.

. Elementos de direito constitucional da República Federal da Alemanha. Original: Grundzüge des verfassungsrechts der bundesrepublik deutschland. Tradução (da $20^{\mathrm{a}}$. edição alemã) de Luís Afonso Heck. Porto Alegre: Sergio Antonio Fabris Editor, 1998.

LIMA, Francisco Gérson Marques de. Fundamentos constitucionais do processo (sob a perspectiva de eficácia dos direitos e garantias fundamentais). São Paulo: Malheiros, 2002.

ROBLES, Gregorio. Los derechos fundamentales e la ética em sociedad actual. Madrid: Civitas, 1995. 